\title{
Le postcolonial et les écritures francophones : pertinence et état des lieux
}

Ndeye BA, Université Ryerson (Canada)

Alexandra ROCH, Université des Antilles (Martinique)

Du point de vue épistémologique, la critique postcoloniale vise l'étude des modes symboliques de gestion du fait historique colonial européen, et de la culture hybride qui se développe dans les espaces colonisés (voir Saïd ; Fanon ; Bhabha ; Spivak). Elle présuppose, dans ses outils herméneutiques, l'analyse des modalités de résistance du sujet colonisé face au fait colonial et à ses manifestations, qui perdurent longtemps après les indépendances et la départementalisation. A cet égard, une approche du postcolonial serait une distinction chronologique, c'est-à-dire un après-colonisation, et une distinction plus épistémologique qui prend en compte autant le pendant et l'après-colonisation, qu'un au-delà du colonial, comme chez Homi Bhabha, dans ces modes symboliques de gestion du fait colonial.

Plus d'une trentaine d'années après son apparition, qu'en est-t-il de la théorie postcoloniale dans les espaces francophones ? Quel état des lieux fait-on de la critique postcoloniale ? Dans un ouvrage paru en 2018, Penser et repenser le postcolonial dans le monde atlantique, Rodolphe Solbiac «s'intéresse aux nouvelles modalités d'une pensée postcoloniale multidimensionnelle qui articule des analyses relevant de la politique des savoirs et des pouvoirs avec des considérations relevant de l'économie, pour explorer et envisager de nouvelles formes de sociabilité »(13).

Hamid Dabashi, quant à lui, interroge, dans Post-Orientalism, Knowledge and Power in a Time of Terror, la pertinence du paradigme postcolonial après le 11 septembre 2001 résultant de l'approche d'Edward Saïd dans L'orientalisme, de celle de Bhabha et de Gayatri Chakravorty Spivak. Au-delà de sa formulation herméneutique ou socio-discursive, la question postcoloniale, à travers son principe directeur de la résistance, touche du doigt le refus, ontologique alors, de l'oppression, ou de l'hégémonie, par l'être humain. C'est ainsi qu'à la suite des travaux de Solbiac et de Dabashi, ce numéro se propose de questionner la situation actuelle de la théorie postcoloniale à travers les écritures francophones. Le paradigme francophone, en soi, ne se comprend pas en dehors du fait historique colonial européen d'hier. Quelles en sont les expressions, reformulations, contestations, réappropriations aujourd'hui, qui influenceraient ou non sa capacité à prendre en charge ou non le texte littéraire francophone? Quelles en sont les applications inusitées, ou différentes, s'il y en a, qui en exprimeraient la permanence ou l'obsolescence, le cas échéant, ne serait-ce que dans le cadre 
du fait littéraire francophone ? C'est à la croisée de cette problématique, philosophique, mais aussi critique et littéraire, que s'inscrivent les contributions à ce dossier. A partir de cas d'étude ponctuels, nos auteurs interrogent les pratiques esthétiques et discursives du texte littéraire francophone.

Dans le premier article, Jonathan Russel Nsangou propose une lecture des romans féminins africains qui va au-delà de la perspective féministe pour y dégager des pistes de portée plus générales. Nsangou en appelle à une féminisation de la critique francophone. Il voit dans les « voix » des femmes de la littérature francophones des « voies» de dépassement des crises postcoloniales. Fétigué Coulibaly, quant à lui, nous offre une analyse critique du théâtre africain. Avec Sony Labou Tansi et Bottey Zadi Zaourou comme exemples, Coulibaly retrace la genèse d'une nouvelle esthétique dramaturgique chez les auteurs africains dits de la deuxième génération qui rompt du mimétisme de leurs ainés. Pour sa part, El hadji Camara remet en question « la promesse de lendemains meilleurs » de la loi sur la départementalisation votée en 1946 aux Antilles. Il montre dans son article que, loin de pallier la crise identitaire de «sociétés dépossédées de leurs valeurs ancestrales», la politique assimilationniste de la départementalisation résulte en une « colonisation 'silencieuse' » encore plus insidieuse. Pour terminer, Laté Lawson-Hellu propose une réactualisation de la perspective postcoloniale sous le paradigme de l'Anthropocène « dans sa relation épistémique à la modernité européenne ou occidentale ». En ce sens, Lawson-Hellu montre d'un point de vue épistémologique que la perspective postcoloniale, ses postulats théoriques et méthodologiques, ne constitue pas la seule approche de questionnement de l'herméneutique des textes littéraires issus des espaces anciennement colonisés.

\section{Bibliographie}

Bhabha, Homi. Les lieux de la culture : une théorie postcoloniale. Tr. Françoise Bouillot. Paris : Payot, 2007.

Dabashi, Hamid. Post-Orientalism, Knowledge and Power in a Time of Terror. Londres : Transaction, 2009.

Fanon, Frantz. Peau noire, masques blancs. Paris : Seuil, 1952.

---. Les damnés de la terre. Paris : Maspero, 1961.

Moura, Jean-Marc. Littératures francophones et théorie postcoloniale. Paris : PUF, 1999.

Saïd, Edward. L'orientalisme, l'Orient créé par l'Occident. Tr. Catherine Malamoud. Paris : Seuil, 1980.

Solbiac, Rodolphe, dir. Penser et repenser le postcolonial dans le monde atlantique. Paris : 
Harmattan, 2018.

Spivak, Gayatri Chakravorty. «Can the Subaltern Speak? » Marxism and the interpretation of Culture. Dir. Cary Nelson et Larry Grossberg. Chicago : U of Illinois P, 1988: 271313. 